\title{
Análisis desde Michel Foucault referentes al cuerpo, la belleza física y el consumo
}

\author{
Alexis Sossa Rojas \\ Universidad Arturo Prat, Iquique, Chile. Email: alexis.sossa@gmail.com
}

\begin{abstract}
Resumen: El presente artículo tiene como objetivo explicar desde los planteamientos de Foucault, cómo funcionan, en términos descriptivos, los fenómenos de consumo que promueven la delgadez y la juventud como características positivas, que nos conducirían a un estado de salud, belleza y felicidad. En este sentido, este artículo proyecta ser tanto una aplicación de la filosofía del autor francés, como "una lectura”, de las diversas que se pueden llevar a cabo desde este autor. Si bien Foucault no estudió directamente este tipo de temáticas, bajo una contextualización de sus planteamientos, lo tomamos como el marco y eje principal que nos guiará a problematizar, vincular y comprender las lógicas que operan en los discursos de belleza física y de consumo.
\end{abstract} del cuerpo.

Palabras clave: Michel Foucault, belleza, consumo, cuerpo, sociología

\section{Analysis uprising from Michel Foucault about the body, physical beauty and consumption}

\begin{abstract}
This article aims to explain uprising from the Foucault's postulates, how, in descriptive terms, the phenomena of consumption that promote thinness and youth work as positive characteristics, that would lead us to a state of health, beauty and happiness. In this respect, this article plans to be an application of the philosophy of the French author and one reading, of several others that can arise from the author's work. Though Foucault did not study directly this type of subject matters, under a contextualization of his approaches, we take it as the framework and main axis that will lead us to problematize, link and understand the logics that operate in the speeches of physical beauty and of consumption.
\end{abstract}

Key words: Michel Foucault, beauty, body, sociology of the body.

\section{Análise a partir de Michel Foucault sobre o corpo, a beleza física e o consumo}

Resumo: Este artigo tem como objetivo explicar a partir das idéias de Foucault, como eles funcionam, em termos descritivos, os fenômenos de consumo que promovam a juventude, a magreza, como características positivas que nos levam a um estado de saúde, beleza e felicidade. Neste sentido, este trabalho pretende ser tanto uma aplicação da filosofia do autor francês como "uma leitura" das diversas que podem ser realizados desde este autor. Embora Foucault não estudou estes temas diretamente sob uma contextualização das suas abordagens, tomamos- 
le como eixo principal a armação para guiar-nos a problematizar e compreender o nexo lógico que operam no discurso da beleza física e de produtos de consumo. corpo.

Palavras-chave: Michel Foucault, beleza, consumo, corpo, sociologia do

$$
* * *
$$

\section{Introducción}

El filósofo francés Foucault procuró exhibir que los pensamientos básicos que las personas razonan como verdades arraigadas sobre la naturaleza humana y la sociedad, varían a lo largo de la historia. Sus interrogaciones y aclaraciones, revelaron las reglas móviles que gobiernan las aseveraciones que pueden ser tomadas como falsas o verdaderas en diferentes épocas, pero que sin duda alguna, terminan por ordenar y controlar a la sociedad y a los individuos, creando todo un sistema de normalización; de convicciones y de realidades, nutridos en juegos de poder.

En esta línea, el propósito del presente artículo es exponer cómo los dispositivos de poder se articulan directamente en el cuerpo, en situaciones, procesos fisiológicos, gustos, emociones, etc. La coexistencia de fenómenos aparentemente tan separados como la estética, la medicina, la publicidad, el cine, por nombrar algunos, y su influencia en las normas culturales que promueven el consumismo y la búsqueda del atractivo físico, nos han apremiado a interrogarnos, al menos en teoría, el carácter natural de la vida sana, bella, o saludable, y nos ha requerido indagar en los elementos tocantes a la racionalidad, sensatez y especulación de las relaciones de poder-saber que se han venido construyendo en la actualidad.

Bajo este orden de ideas, se debe explicitar que en la lógica que opera Foucault, las reflexiones más que encontrar la verdad de las cosas, inquieren ser instrumentos para explicar. De esta suerte, para entender nuestra sociedad, para comprender cómo las concepciones de belleza física y de consumo surgen como problemáticas importantes e influyentes, hay que hacer visible y analizar los discursos y las relaciones saber/poder que están inmersas en ellas. Pues, la hipótesis general del trabajo que realizó Foucault es que las relaciones, las estrategias, y las tecnologías del poder nos atraviesan, éstas producen saberes y verdades que le son útiles, esto a través de un proceso de naturalización que se va volviendo cada vez más invisible.

Para objeto de lo ya planteado, se dividirá el artículo en cinco secciones. En la primera se expondrá por qué la utilización de Foucault como autor para indagar en los fenómenos de consumo y belleza física. La segunda presenta las reflexiones de Foucault, principalmente en referencia a sus conceptos de verdad, poder y disciplina. La tercera expone las intrincaciones entre consumo y subjetividad. La cuarta nos habla respecto de cómo se liga la belleza física dentro de los procesos de consumo y qué rol juega. Finalmente se presentan conclusiones generales. 


\section{Por qué Foucault}

Foucault estudió al cuerpo como un eje principal en sus reflexiones, para él, el cuerpo es un texto donde se escribe la realidad social. Bajo esta inclinación, gran parte de sus investigaciones pasaron por examinar las formas de gobierno encaminadas a vigilar y orientar el comportamiento individual, a través de distintas instituciones; la medicina, la escuela, la fábrica, el ejército, etc. Y cómo a través de estas entidades se dota al individuo, de estrictas normas corporales; de una manera de actuar y de obedecer, que de ser exitosa, es un garante del orden social.

Siguiendo los planteamientos de Foucault, y sobre todo aquellos formulados en su etapa genealógica, es vital comprender las relaciones entre verdad, saber y poder. Percibir la singularidad de los sucesos, pero no para trazar la curva lenta de su evolución, no buscar orígenes, sino que por el contrario, ocuparse de las meticulosidades, de lo azares, de lo irrisorio que suele encontrarse en los comienzos (Foucault 1992a). La mirada genealógica de Foucault nos invita a conducir el razonamiento a partir de lo presente, lo que es válido para nosotros, y a partir de ahí, configurar embrollos de sucesos no siempre advertidos, no siempre controlables, pero sí siempre rastreables y siempre atravesados por el poder.

Si el consumo es un campo de ejercicio del poder, éste puede ser entendido bajo los planteamientos de Foucault, pues como él establece (Foucault, 1998, 1992a, 1993), continúan existiendo los grandes mecanismos secretos mediante los cuales una sociedad transmite su saber, y se perpetúa a sí misma bajo una apariencia de saber. Estos aparatos están todavía en pie: periódicos, televisión, hospitales, etc. Por lo que si se quiere estudiar el poder, "Se trata de estudiarlo partiendo de las técnicas y de las tácticas de dominación” (Foucault 1992a: 147), que en nuestro caso será, a partir de los discursos, de las normas, a partir de las relaciones de poder que están presentes en las concepciones de belleza física y consumo.

En consecuencia, miramos hacia Foucault de una manera heurística, como un autor que brinda un instrumental conceptual variado y esclarecedor, mas sus conceptos no los comprendemos como fines en sí mismos, sino como un medio para su utilización en problemas específicos. En este caso, para advertir la lógica que opera al interior de las ideas de consumo y de belleza física actual, para revelar aquello que está muchas veces tan incorporado que se vuelve oculto.

\section{Foucault, verdad, poder y disciplina}

Para Foucault (1992a) existe una economía política de la verdad, la "verdad" está centrada en la forma del discurso científico y en las instituciones que lo producen; está sometida a una constante incitación económica y es objeto bajo formas diversas de una inmensa difusión y consumo; es 
producida y transmitida bajo el control no exclusivo pero sí dominante de algunos aparatos políticos o económicos. Por último, es el núcleo de todo un debate político y de todo un enfrentamiento social. La verdad está ligada a los sistemas de poder que la producen y la sostienen, y a efectos de poder que ella induce y reproduce; todo esto constituye el régimen de verdad.

En este contexto, lo que interesó a Foucault fue ver cómo existe una producción de discursos verdaderos, a modo de ejemplo, llamar “desviado” a alguien tiene consecuencias diferentes de llamarlo “enfermo”. De ahí la importancia que Foucault le da a los discursos, y a sus cambios en la historia. Asimismo, recordemos que "la embriaguez del siglo XIX se transformó, en el siglo XX, en la enfermedad del alcoholismo, mientras que la homosexualidad como pecado pasó a ser, por vía de la categoría enfermedad, simplemente una preferencia personal” (Turner 1989: 251). “... la verdad, desprovista de todo contenido ontológico-objetivo, no es otra cosa que un efecto, un producto, deberíamos decir, de las estrategias sociales, de las relaciones de poder" (Castro 1995: 17). Las relaciones de verdad son relaciones de fuerza inherentes a las prácticas que se observan y codifican en los efectos de su propio movimiento.

La verdad es de este mundo; es originada aquí gracias a múltiples imposiciones. Tiene aquí efectos reglamentados de poder. Cada sociedad tiene su régimen de verdad, su “política general de la verdad” (Foucault 1992a). Es decir, los tipos de discursos que ella acoge y hace funcionar como verdaderos; los mecanismos y las instancias que permiten distinguir los enunciados falsos, la manera de sancionarlos; las técnicas y los procedimientos que son valorizados para la obtención de la verdad; y el estatuto de aquellos encargados de decir qué es lo que funciona como verdadero. No hay verdad última de las cosas, sino funcionamiento de verdades ficticias (Castro 2008).

Foucault propone que la verdad está en estrecha relación con las relaciones saber-poder. El poder se encuentra en el hombre mismo, no es algo externo que lo oprima o esclavice. En tal sentido, el razonamiento al poder, no consigue ser clasificado como algo bueno o malo, ya que el poder se esboza como una extensa red de relaciones. No existen explotados, porque el poder no es una propiedad, vale decir, no es algo de la exclusividad de una persona o de un grupo determinado (Foucault 1993). Si Foucault cambia la mirada al poder, lo hace para demostrar que la construcción del conocimiento, de la verdad y de la propia subjetividad, no son ni universales, ni azarosas; pasan por estrategias concretas de poder.

En consecuencia, el poder es la capacidad de conducir las conductas, de hacer circular a la gente por un camino determinado, sin por ello ejercer algún tipo de violencia. El poder es una fuerza que en esencia es productiva, puede conseguir la conversión del espíritu y el encauzamiento de la conducta de los individuos. Es siempre ejercido en una relación y todas las personas poseen poder. 
En este sentido, cabe mencionar la categoría cuerpo, pues para Foucault resulta superlativa, desde lo más individual el cuerpo encarna un pequeño poder, un micro-poder; este micro-poder está en relación con otros micro poderes, y esta articulación se hace palpable en diversos campos, como por ejemplo: en el campo social, económico, político, cultural, entre otros. De las relaciones de los micro poderes, resulta la creación de normas, estipulaciones, acuerdos, en fin, diversas ilaciones que involucran al cuerpo y a la sociedad.

Ahora bien, una forma de ejercicio del poder que tiene por objeto los cuerpos y por objetivo su normalización, es la disciplina, esta tecnología obliga a la homogeneidad anulando todo aquello que se escape de la norma. "La disciplina es una técnica de ejercicio de poder que no fue totalmente inventada sino elaborada en sus principios fundamentales durante el siglo XVIII” (Foucault 1993: 162). Es decir, construida a partir del momento en que el ejercicio monárquico del poder se volvió demasiado costoso y poco eficaz. Como se presenta en Vigilar y castigar: "Ha habido, en el curso de la edad clásica, todo un descubrimiento del cuerpo como objeto y blanco de poder. Podrían encontrarse fácilmente signos de esta gran atención dedicada entonces al cuerpo, al cuerpo que se manipula, al que se da forma, que se educa, que obedece, que responde, que se vuelve hábil o cuyas fuerzas se multiplican” (Foucault 1998c: 140).

Así, el cuerpo ha estado directamente inmerso en una estrategia de poder, en un campo político; "las relaciones de poder operan sobre él una presa inmediata; lo cercan, lo marcan, lo doman, lo someten a suplicio, lo fuerzan a unos trabajos, lo obligan a unas ceremonias, exigen de él unos signos" (Ibid: 32). Esto se va haciendo factible, en gran medida, por el proceso de disciplinamiento, vigilancia y normalización al que nos vemos sometidos desde que nacemos en una determinada sociedad y que poco a poco nos va constituyendo como sujetos.

“La disciplina 'fabrica' individuos; es la técnica específica de un poder que se da a los individuos a la vez como objetos y como instrumentos de su ejercicio" (Ibid: 175). En otras palabras, por medio de la disciplina se puede enseñar a los sujetos para que sean útiles y "El cuerpo sólo se convierte en fuerza útil cuando es a la vez cuerpo productivo y cuerpo sometido” (Ibid: 32). Por tanto, la disciplina busca fiscalizar y controlar la conducta, sus comportamientos, sus aptitudes, sus preferencias, a través de diferentes formas. "A estos métodos que permiten el control minucioso de las operaciones del cuerpo, que garantizan la sujeción constante de sus fuerzas y les imponen una relación de docilidad-utilidad, es a lo que se puede llamar las “disciplinas'” (Ibid: 141).

Vistos sucintamente estos tres conceptos: verdad, poder y disciplina, podemos ir dando cuenta de cómo se va dando la mutación personasujeto. Para ahondar en este punto, Foucault nos presenta dos concepciones muy relevantes, que no son incompatibles, pues están atravesadas por un plexo de relaciones: La primera es el anatomopoder, que se refiere a las 
formas de educar, disciplinar el cuerpo individual, de volverlo un cuerpo útil y dócil. La segunda, es la biopolítica, que remite a la manera como se emplean formas políticas de administración de la vida de una población. Por ejemplo: patrocinio de los procesos biológicos como el nacimiento, la mortalidad, la salud, etc. Estos dos conjuntos de técnicas conforman lo que Foucault denomina: biopoder. Aquí, ambos conceptos operan medularmente para producir productividad, en el primer caso: en una persona, en el segundo: en toda la sociedad.

El surgimiento del biopoder trae consigo consecuencias, como un desplazamiento en importancia de la norma a expensas de la ley, pues un poder que tiene como objetivo gestionar la vida necesita mecanismos permanentes y reguladores. Un poder así más que desplegar prohibiciones y represiones, necesita clasificar, medir, jerarquizar y excluir, teniendo como parámetro la norma, es decir, estableciendo estrategias de normalización.

Foucault (1998a) considera que el biopoder ha sido un elemento indispensable para el desarrollo del capitalismo. Ha servido para asegurar la inserción controlada de los cuerpos en el aparato productivo, y para ajustar los fenómenos de la población a los procesos económicos. De ahí la importancia creciente de la norma y, consiguientemente, de la normalidad. La norma es lo que puede aplicarse tanto a un cuerpo que se quiere disciplinar cuanto a una población que se quiere regularizar.

Foucault delimita que existe un saber del cuerpo que no es exactamente la sabiduría de su funcionamiento, y un dominio de sus fuerzas que es más que la capacidad de vencerlas: este saber y este dominio constituyen lo que podría llamarse la tecnología política del cuerpo. "Indudablemente, esta tecnología es difusa, rara vez formulada en discursos continuos y sistemáticos; se compone a menudo de elementos y de fragmentos, y utiliza unas herramientas o unos procedimientos inconexos" (Foucault 1998c: 33).

De este modo, el poder encuentra el núcleo mismo de los individuos, alcanza su cuerpo, se inserta en sus gestos, sus actitudes, sus discursos, su aprendizaje, su vida cotidiana, su sexualidad. "El siglo XVIII ha encontrado un régimen por así decir sináptico del poder, de su ejercicio en el cuerpo social. No por debajo del cuerpo social” (Foucault 1992a: 89). En consecuencia, la ocurrencia de que surjan creencias y disposiciones como verdaderas, obedecen a hechos objetivos, a toda una construcción cultural e histórica, a una política que las ha convertido en indudables, constituyendo sujetos sujetados al poder y al saber de turno.

\section{Foucault, consumo y subjetividad}

La transformación del sistema de producción y acumulación capitalista, ha generado un tipo de discurso y de sociedad, en la que el consumo es uno de los principales mecanismos de integración social (Salvat, 1975; Ewen, 1992), estas relaciones de fuerzas, o de poder, son estratégicas, 
microfísicas, difusas, determinan singularidades y subjetividades. Ahora bien, como se expuso, para Foucault la subjetividad pasa por un proceso de normalización, y los cuerpos no sólo son la materia prima donde se inscribe o asienta el orden social, al disciplinarlos, sino uno de los recursos que lo puntualizan, expresan y reproducen. “... el sujeto se forma a partir de una serie de procesos y sistemas que no responden a una naturaleza originaria de la subjetividad, sino que obedecen a condiciones históricas, políticas y sociales” (Castro 2008: 173). Y en la actual sociedad de consumo, existen unas prácticas discursivas muy ligadas a la estimulación de la belleza física $\mathrm{y}$ al consumo como fines en sí mismos ${ }^{1}$.

En este sentido, estamos concibiendo el concepto de sociedad de consumo, en contraposición con el de sociedad de necesidades de períodos culturales precedentes. Pues, este cambio ha dado paso a la instauración de necesidades artificiales en el individuo; su subjetividad ha sido invadida con imposiciones desde el sistema de producción; las multinacionales, la publicidad y la moda, por nombrar algunos. En esta lógica, las necesidades pasan de ser vitales a impuestas. El individuo transita de tener la necesidad de comer, a requerir determinados productos light, diet, etc. Esto es debido a que la acción se acomoda y encamina en función de las exigencias del sistema productivo. Las necesidades buscan alcanzar la condición de trascendentes, mostrando al consumo como la vía hacia la consecución de la perfección, la autoestima y el éxito social.

"Si el problema de los equilibrios mal establecidos de los siglos anteriores consistía en producir lo necesario para cubrir las necesidades, el nuevo problema consiste en crear las necesidades para poder consumir lo que se produce” (Salvat 1975: 32). En esta lógica, el consumismo busca representar la forma posmoderna de libertad (Rojas 1992), en donde el individuo cree que actúa libremente, pero su independencia usualmente choca con las prohibiciones establecidas por la convivencia.

Foucault exhibe que analizar un discurso es tratar de llegar a la red de estructuras que conforman el discurso, para ver el momento en que comienzan a desvelarse los elementos ausentes y los presentes, su ubicación y su significado, buscando la relación entre el sujeto, su discurso y el discurso social ideal. Es así como el trabajo, la producción y el consumo, ponen en juego una búsqueda en torno a la construcción de un tipo de subjetividad cada vez más individualista. El poder opera aquí, ya no sólo para crear, vigilar, y normalizar una masa de trabajadores, sino para introducir y disciplinar consumidores. Existe "Una 'anatomía política', que es igualmente una 'mecánica del poder’, [...] (la que) define cómo se puede hacer presa en el cuerpo de los demás, no simplemente para que ellos hagan lo que se desea, sino para que operen como se quiere, con las técnicas, según la rapidez y la eficacia que se determina” (Foucault 1998c: 141)².

Foucault (1992a) nos revela que estamos subordinados a la verdad, en la razón de que la verdad establece, crea normas, elabora el discurso considerado normal, empujando efectos de poder. Somos juz- 
gados, clasificados, destinados a vivir de un cierto modo, en función de discursos verdaderos que sobrellevan derivaciones de poder. El poder no renuncia examinarnos, exige de nosotros una existencia, institucionaliza la verdad, la profesionaliza, la recompensa, nos invade nuestra subjetividad.

Adoptando este lineamiento, el cuerpo actualmente se vuelve ya no un "envoltorio", sino que se erige como un protagonista de las sociedades modernas, una expresión y emblema de libertad, identidad, belleza, salud, prestigio, perfección, etc. El físico pasa a ser una valiosa materia manipulable para la persona que lo encarna. Igualmente, “La 'subjetividad' del 'sujeto', o sea su carácter de tal y todo aquello que esa subjetividad le permite lograr, está abocada plenamente a la interminable tarea de ser y seguir siendo un artículo vendible. La característica más prominente de la sociedad de consumidores -por cuidadosamente que haya sido escondida o encubiertaes su capacidad de transformar a los consumidores en productos consumibles..." (Bauman 2007: 26).

Bajo esta lógica, el cuerpo adviene a ser tomado más allá de instituciones disciplinadoras como la cárcel o la escuela, ahora se ha ido implantando como un claro objeto de consumo presente en la cotidianidad. Esto entraría en correspondencia con una nueva forma de disciplinamiento del cuerpo sugerida, enseñada y reproducida por distintos discursos y medios. Es decir, el término imagen corporal, que pertenece al terreno de lo abstracto, es una construcción simbólica que se ha vuelto valiosa e instrumental, esto a través de los cambios en la edificación del cuerpo como hecho subjetivo mediante el cual el individuo moderno se concibe a sí mismo, y que se reflejan en las transformaciones de los discursos sobre la apropiación y la importancia de la belleza física.

En las sociedades capitalistas industrializadas, la informática y los medios de comunicación de masas, integran un substancial papel en el ejercicio de controlar, disciplinar y normalizar (Bayo-Borras 2008; Cabrices 2007; Moreno 2009; Ramírez 2007), volviéndose un pilar fundamental en la mantención y normalización del actual sistema de consumo. Sus mensajes, tanto en la forma como en el fondo, portan representaciones normativas que obedecen a intereses específicos.

Ahora bien, como lo esboza Foucault (1998c), la disciplina es una tecnología sugerida, no puede identificarse claramente ni con una institución ni con un aparato. Es un tipo de ejercicio del poder, una modalidad para ejercerlo, implicando todo un conjunto de instrumentos, de técnicas, de niveles de aplicación, es una "física” o una "anatomía” del poder. Así, evocando el concepto de anatomopoder, vemos cómo esta modalidad es aprovechada como tipo de poder para guiar a los cuerpos, para introducirse en lo más íntimo, inculcándoles una manera de actuar y de pensar, siendo así que se perciben influencias tanto negativas como positivas. En este proceso el sujeto adquiere autonomía, poder y saber, el que utiliza para interrelacionarse con la sociedad. Y en la actual, es claro, hay un estímulo 
al consumo y al atractivo físico, pero más que atribuirlo a una institución, se debe entender que esta está influenciada en un juego de poder ${ }^{3}$.

Prácticas como el consumo, ligado a los procesos actuales de individualización, hacen que consumir hoy no tenga como esencia el satisfacer necesidades, ya que el espíritu que lo mueve son los caprichos o el deseo, algo mucho más vago que las necesidades. Es un impulso autogenerado que no demanda defensa ni fundamento. "el capitalismo moderno tiende a fomentar el cálculo hedonista y la personalidad narcisista. La cultura del consumidor requiere, no de la supresión del deseo, sino de su manufactura, extensión y detallamiento” (Turner 1989: 52).

Asimismo, "El propósito crucial y decisivo del consumo en una sociedad de consumidores [...] no es satisfacer necesidades, deseos o apetitos, sino en convertir y reconvertir al consumidor en producto, elevar el estatus de los consumidores al de bienes de cambio vendibles" (Bauman 2007: 83). Por lo tanto, hacer de uno mismo un producto negociable, así como también responder rápida y eficazmente a las tentaciones del mercado, es responsabilidad y gravamen de cada uno.

Foucault explicita que para que los discursos y fuerzas operen, no sólo se necesita de instancias y sujetos que creen estas subjetividades, que disciplinen y normalicen, sino que también se debe vigilar que así sea. De esta manera, existe todo un saber, todo un sostén de antecedentes, toda una analítica respecto de las preferencias, gustos y tendencias de las personas ${ }^{4}$. Un rasgo peculiar del modo de producción capitalista consiste, entonces, en que ésta no requiere una forma ascética del deseo; los placeres son de hecho manipulados y producidos por el proceso de mercantilización y elaborados por el circuito del consumo. "El régimen de los cuerpos no está ya más fundado en un principio de restricción ascética, sino en el cálculo hedonista y la amplificación del deseo. El ascetismo ha sido transformado en prácticas que promueven al cuerpo en aras del sensualismo comercial” (Turner 1989: 299 - 300).

En este sentido, la publicidad es uno de los dispositivos de normativización y significación más importante en la producción de sentidos sociales dentro de las sociedades contemporáneas. Es un sistema que goza de todo un régimen construido a través de un determinado discurso, y aun cuando puede tener un público objetivo, sus recomendaciones quedan enunciadas para todos, aunque no los busquemos, por lo que en todo momento nos recuerdan cuál es la norma, qué es lo que está a la moda, etc.

En el consumo actual los objetos ya no apuntan a su utilidad, sino que se busca en ellos una cuantía en tanto símbolo, pues se crea una extensión que les agracia incorporar elementos que van más allá de su razón práctica. La publicidad no comunica las características objetivas de aquello que promociona, sino más bien persigue construir en torno a ellos, y sobre ellos, combinaciones de significados y simbolizaciones que los doten de una cierta plusvalía, haciendo de ellos objetos indispensables. 


\section{Foucault, belleza y consumo}

En las últimas seis décadas el saber que se ha entregado a través de distintos medios, es el del consumo y la subjetivación del valor estético del cuerpo por sobre todo los otros valores que en él están inmersos (valor simbólico, cultural, religioso, etc.). Incluso, se ha establecido un consumo de los discursos corporales; los cuerpos deben ser bellos, saludables, bronceados, delgados, jóvenes. Ha ocurrido un traslado del término de belleza hacia el plano físico; la definición de belleza se ha impregnado de marketing, pues esta pasa a representar un capital simbólico que puede adquirirse, perderse o incluso comprarse ${ }^{5}$.

De esta manera, podemos distinguir que una sociedad regida por la racionalidad del mercado en donde se compra la belleza y la delgadez, se revela una situación paradójica, "la Organización Mundial de la Salud (OMS) alerta sobre la obesidad como epidemia mundial y la Organización de Naciones Unidas para la Agricultura y la Alimentación (FAO) sobre la desnutrición a nivel también mundial... pero ambas como enfermedades de la pobreza" (Aguirre 2004: 34). Vale decir, "la mayoría de los gordos no son ricos sino pobres y la gordura está situada en el polo opuesto de la belleza. Existe, además, cierta reprobación moral que categoriza a los gordos como personas autocomplacientes, débiles de carácter y abandonadas en todo lo que se refiere al cuidado personal” (Ibid: 19).

Los medios de comunicación de masas proclaman modelos de excesiva delgadez que patrocinan un arquetipo de belleza, que en el caso de las mujeres $^{6}$, está representado por jóvenes cuya estatura y peso son características excepcionales, las llamadas top-models. La publicidad, la moda, son parte de las instancias que han reformado el valor de la delgadez. La flaqueza se ha tornado distintivo imprescindible asociado a la autonomía, al éxito profesional, social y, desde luego, al éxito erótico. En este sentido, el mercado ha sabido sacar provecho, pues la oferta es amplia: gimnasios, centros de belleza, cirugías estéticas, suplementos nutricionales, prendas que hacen lucir delgado; o ayudan a adelgazar, productos dietéticos, cosméticos, fármacos, libros, vídeos especializados, máquinas para la ejercitación, etcétera.

La contribución de los medios al paroxismo de la estética personal no se limita a la revaloración de la imagen, pues la fotografía, Hollywood, la televisión, Internet, etc., no sólo nos muestran que hay que pensar y apreciar la estética personal; también nos dictan cómo hay que pensarla y valorarla. Existe un tipo de consumo que toma al cuerpo como su objetivo, imponiendo unas normas. Y este tipo de prácticas, de atención y culto al cuerpo, se ha entendido como una nueva forma de consumo, paradojalmente llamado consumo cultural.

Ahora bien, no todo pasa por el mercado, en una sociedad disciplinaria el patrón de medida será la norma (Foucault 1998c), pero, quien no la cumpla, estará más individualizado que el que la cumple. Por ejemplo, lo 
normal es estar sano, si una persona tuviese alguna enfermedad, se le obligará a que se someta a registro, observaciones, visitas al médico, exámenes, etc. He aquí algo relevante, en la medida que los sujetos se individualizan, el poder se desindividualiza, corre por todos los canales de circulación posible colocando mayor énfasis sólo en aquellos que desobedecen o se alejan de la norma, por ende, la observación y la vigilancia, provienen de más allá del propio sistema de consumo.

Antiguamente las fajas y los corsés reprimían las caderas y formaba las cinturas ceñidas, finas, luego vino el “corsé social”, el apremio tanto de los pares, como de los modelos y arquetipos que circulan por los medios de comunicación. Por ejemplo, patrones de mujeres apuestas, que las marcas de innumerables artículos promueven, por citar un caso: rubia, joven, curvilínea, ojos celestes y delgadísima; ésa que, de tanto observarla en la televisión, en fotografías, en gigantografías, etcétera, la gente se familiariza y educa juzgando que es el patrón correcto.

Dado lo anterior, cabe especificar que es a la mujer a la que mayoritariamente se le invade con estas ideas (Le Breton 2002; Amigo 2002; Ewen 1992; Turner 1989; Eco 2007; Morris 2005), pues en muchas situaciones, masculinidad es sinónimo, entre otras cosas, de serenidad por el aspecto propio, mientras que la feminidad encarna una gran preocupación en tal sentido.

Bajo este orden de ideas, el deleite de ser joven, ya sea con la asistencia de la cirugía o del ejercicio físico, hermanado a todos los accesorios que son posibles de comprar, han proporcionado un mercado distinto; el de la belleza como la gran mercancía. Es este mundo subjetivado en donde el cuerpo hermoso y delgado es un nuevo santuario. El control del peso se transforma para muchos en el eje de la vida, el punto de partida de la gran carrera, ser joven cada vez más, en la medida en que se es menos. Buscar nuevos atributos al cuerpo, es cambiar la imagen, buscar mayor aprobación $^{7}$, es caminar hacia estar en forma y ser feliz. No obstante, Foucault diría, es obedecer al sistema normalizador imperante.

El consumo moderno se vislumbra como productor de una población pasiva y subordinada que, muchas veces, no es capaz de distinguir sus necesidades reales. El cuerpo como construcción cultural, en esta época hay que manipularlo para venderlo. Es un objeto palpable que posee influencia y por lo tanto se lo comercializa. De esta forma se explica el que para muchas mujeres hoy en día ser bellas se convierta en una fuente de ingresos. El físico en su puesta en escena actual, funciona según las leyes de la economía de los discursos; el individuo debe tomarse a sí mismo como objeto, como el objeto más fausto, que puede instituirse como proyecto económico de rentabilidad. Featherstone citado por Turner señala: "Dentro de la cultura del consumidor el cuerpo es proclamado como un vehículo del placer: es deseable y deseoso, y cuanto más se aproxima el cuerpo real a las imágenes idealizadas de juventud, salud, belleza, más alto es su valor de cambio" (1989: 213). 
De esta suerte, “El cuerpo humano está plantado como un alter ego del hombre: sigue siendo signo del hombre, sin ser más hombre, ya que operaciones en su contra se volvieron legítimas. Estas provocarían horror si se produjeran sobre el hombre por completo y no sobre un cuerpo que se piensa de manera independiente del hombre” (Le Breton 2002: 75). El cuerpo, se vuelve sólo un conjunto de piezas o formas que pertenecen y están, subordinadas al hombre, pero, que no necesariamente son el hombre ${ }^{8}$.

Las estructuras actuales de producción/consumo, proporcionan al individuo una doble representación de su cuerpo: como capital y como fetiche. El cuerpo naciente se exterioriza en esta perspectiva de inversión y signo social. Así, el cuerpo es un “signo”, un “mensaje” que habla de su propietario. La apariencia física surge como un símbolo que puede resumir el carácter, la moral y los valores de una persona. Le Breton nos menciona: "El hombre alimenta con su cuerpo, percibido como su mejor valor, una relación maternal de tiernos cuidados, de la que extrae, al mismo tiempo, un beneficio narcisista y social, pues sabe que a partir de él, en ciertos ámbitos, se establece el juicio de los demás” (Le Breton 2002: 82-83). Por lo tanto, teniendo en vista este tipo de fenómenos y vinculándolos con lo planteado por Foucault, podemos exponer que el poder de normalización operante no fuerza ni inhabilita; sino que delimita los términos de lo normal y lo anormal, incitando la producción de ciertos actos, gestos y discursos.

Foucault nos muestra que el poder crea, produce realidades, se inventó al demente, al delincuente o al anormal, en esta misma lógica, los grupos excluidos por los discursos estéticos comerciales los componen los viejos, los pobres, los gordos, los discapacitados, los morenos ${ }^{9}$, entre muchos otros. Son la moda y los estereotipos los que señalan qué es normal y qué no lo es, qué es bello y qué es feo. El discurso obviamente tiene sesgos. El modelo estético, adquiere características de moral, de ético, ya que lo bueno, lo moral, se asocia a la belleza (Llaguno 2002; Avenatti 2006; Mijares 2006), belleza entendida desde la flaqueza y la juventud, alejarse de ella es ser estigmatizado y castigado por la sociedad.

Esta rigidez de los cánones estéticos que impone la cultura occidental de la imagen, supone para las personas una batalla contra el tiempo para conseguir ser aceptadas socialmente, produciendo problemas de inseguridad y de no aceptación del propio cuerpo. Las probabilidades de sentirse incomodo en el cuerpo de uno, son tanto más fuertes en la medida que es mayor la desproporción entre el cuerpo socialmente exigido y la relación práctica con el cuerpo que imponen las miradas y las reacciones de los demás (Bourdieu 1986).

Las imágenes transmitidas por los medios de comunicación refuerzan un estilo de vida donde el cuidado del cuerpo (no sólo ejercicio físico, sino la cosmética, el vestido, etc.) tiene un lugar central. El “prestigio” que goza el cuerpo bello hace que frecuentemente se adhieran a estas prácticas personas que buscan en él un camino para mejorar su posición en la estructura social. Distinguen en el cuerpo una de las pocas áreas donde pueden 
ejercer un control cotidiano (a través del ejercicio físico, las dietas, el ornamento, etc.), y no como la política, la economía o la ley, que las consideran extrañas. He aquí donde los planteamientos de Foucault cobran fuerza, pues la relación de poder se vuelve invisible, ocultando que esto obedece a una estrategia de poder.

El mercado masivo al hacer del cuerpo su objetivo, lo ha transformado en mercancía, y en un medio para la manufactura y distribución de productos, pues no sólo se puede comprar un producto que "embellezca", sino que un cuerpo bello vende. La publicidad, las propagandas están plagadas de imágenes que señalan cuerpos delgados, esbeltos y agraciados, para ofrecer cualquier cosa.

El fenómeno del consumo, o si se quiere el mercado donde se hace patente el consumo, estipula cada a la belleza como ideal de verdad y probidad. Pero como lo señala Ewen: "hay contradicciones entre la verdad y la verdad comercial” (1992: 308). Lo que se da por sentado, muchas veces no es más que una ilusión sugerida que promueve al consumo. El mercado busca que la concepción de la imagen personal, nuestro propio cuerpo, sea un reflejo que determina nuestro éxito, y que su prolijidad irrumpa como algo infalible para competir con los demás. "En respuesta también a la sublevación del cuerpo, encontraréis una nueva inversión que no se presenta ya bajo la forma de control represión, sino bajo la de control-estimulación: «iPonte desnudo... pero sé delgado, hermoso, bronceado!» A cada movimiento de uno de los adversarios responde el movimiento del otro" (Foucault 1992a: 105).

En definitiva, el éxito en perfeccionar el cuerpo dotado de hermosura como un remanente del ser moderno, está asumido por una gran parte de la población, situación que se condice claramente con la economía de mercado, que como lo manifiesta Castells (1999), es una economía que basándose en la tecnología de la información, proporciona la base material indispensable para la difusión de aquello que se intenta vender. Y como el consumo actual no se basa en la regulación del deseo, sino en la liberación de los anhelos, ya que el sujeto hoy se exterioriza a sí mismo por medio de lo que posee. Qué mejor que poseer un cuerpo estéticamente bien parecido.

Las relaciones de poder, la mirada, operan aquí no sólo disciplinando y normalizando a la población, sino que haciéndose tan vigilante, como en el panoptismo carcelario, que los sujetos llegan a vigilarse a sí mismos y a los demás; reproducen el patrón que se les ha entregado. “... el individuo se convierte en la fuente de su propio sometimiento. Nada puede ser más rentable como tecnología política de los cuerpos que esta incorporación individual de la vigilancia” (Castro 2008: 152). Una vez implantada la efectividad y presencia de la observación, es el propio sujeto el que se autovigila, se auto-castiga, se auto-reprime, se auto-controla.

El cuerpo “diez”, el poseedor de "sex-appeal”, de buen “look”, el que da "la línea”, "la forma”, "el tipo”, etc., es un cuerpo constituido a 
voluntad o comprado. Esta aspiración se plasma en la obtención del cuerpo joven, seductor, guapo, fibroso, etc. Sólo a partir del cuerpo y la belleza entendidas como posesión individual, y no como dimensión del ser, es que puede operarse sobre ellas y convertirse en un proyecto.

Los discursos estéticos que operan en el actual sistema de consumo no ven al cuerpo como un todo, sino como elementos más, o menos armónicos. Así, por ejemplo, las personas que se someten a cirugías estéticas, se conciben a sí mismas como un conjunto de regiones inconexas: se corrigen la nariz, y luego descubren que sus orejas tampoco están bien, y nuevamente recurren a una cirugía. Su cuerpo no es una unidad, sino sólo un compendió de elementos. "Nuestro cuerpo es ya casi desechable. No importa realmente la capacidad física de nuestro cuerpo. Atrae más su "forma", no las formalidades” (De la Parra 2002: 218).

De esta manera, la medicina y los médicos han contribuido significativamente a extender el descrédito social de la obesidad y del sobrepeso (Gil-Romo 2007), situación que históricamente aparece hace pocas décadas, el discurso varió, y de los cuerpos abundantes pasamos a cuerpos escuálidos. Situación que se reflejó tanto en las argumentaciones desde la publicidad como en el de los especialistas, pensemos que "Todavía hasta los años 50 la publicidad propone un cuerpo floreciente y lleno, las mujeres gruesas son las mujeres soñadas por los hombres y el modelo anhelado y soñado por las mujeres” (Biber 2002: 10). Igualmente, el estar con unos kilos demás era sinónimo de estar "sanito”.

Esta presión por poseer atractivo físico, por mantener la figura delgada, así como de ajustarse a las normas estéticas, han desarrollado problemas a gran escala como los Trastornos de la Conducta Alimentaria (TCA), que por nombrar el caso de la imagen corporal que los anoréxicos tienen de sí mismos, pasa por una idea desdibujada. Su situación es la de auto rechazar su apariencia. Se juzgan gordas y gruesas, aún cuando están desnutridas, famélicas. Es un enfermo que tiene una sensatez incierta de su aspecto ${ }^{10}$ que lo lleva incluso a la autolesión.

Los especialistas reparan (Biber 2002; Marin 2002; Llaguno 2002; Morris 2005; Colombo 2006; Perena 2007; Gil-Romo 2007; Sánchez 2007; Valor 2007) que cuando personas con problemas de TCA, exponen estar gordas o gordos, delimitan también el sentirse no suficientemente buenos para ser aceptados, no se conciben agradables, competentes, bellos. No es de extrañar que bajo la gran presión social por la estética, el que no se ajusta a los cánones puede verse excluido, aún más, se culpa a los excluidos de su propia exclusión.

Foucault aclara en relación a los sujetos que "El dominio, la conciencia de su cuerpo no han podido ser adquiridos más que por el efecto de la ocupación del cuerpo por el poder: la gimnasia, los ejercicios, el desarrollo muscular, la desnudez, la exaltación del cuerpo bello... todo está en la línea que conduce al deseo del propio cuerpo mediante un trabajo insis- 
tente, obstinado, meticuloso que el poder ha ejercido sobre el cuerpo de los niños, de los soldados, sobre el cuerpo sano” (Foucault 1992a: 104).

De esta manera, hemos establecido que se les impone a los individuos, a través de ciertos discursos; tácticas de disciplinas individualizantes, normas culturales, prácticas legitimas e ilegitimas, mas esta situación es microfísica, pues no es una imposición agresiva, áspera, sino que el poder es una situación, una relación, y por tanto mediante el desenvolvimiento social del individuo, va adquiriendo, por ejemplo, ciertas disciplinas, muchas veces sin darse cuenta.

\section{Conclusión}

La obra de Foucault constituye una caja de herramientas importante a la hora de hacer inteligibles ideas, acciones y simbolismos que permiten una coherencia explicativa y descriptiva de la abrumadora evidencia de las relaciones sociales. Su percepción del poder pasó por comprender la multiplicidad de las relaciones de fuerza inmanentes y propias del dominio en que se ejercen, o al contrario, los desplazamientos, las contradicciones que aíslan a unas de otras, por último, cómo se tornan efectivas, y cuyo esquema general o cristalización institucional toma forma en las normas culturales, en las hegemonías sociales, etc.

Foucault manifestó que se debe buscar una historia de la verdad, pero no de qué es la verdad, sino un análisis de los "juegos de verdad" (Foucault 1998b), así parafraseándolo, lo que hemos buscado develar en relación a la belleza y el consumo es ¿̇a través de qué juegos de verdad se da el hombre a pensar su ser propio cuando se percibe como feo, cuando se contempla, se juzga y se castiga como gordo o deslucido? En este sentido, hemos tomado como principal objetivo el mostrar la determinación y la libertad del hombre no atacando a un grupo a una institución o a una clase, sino vislumbrando las técnicas particulares de una forma de poder. Y en relación a lo expuesto, hemos señalado cómo las normas de belleza física y de consumo se van entrometiendo en lo más íntimo de las personas. Existe un poder que se ejerce sobre la vida cotidiana, clasifica a los individuos en categorías, les impone una ley de verdad que deben reconocer y que los otros han de reconocer en ellos. Es una forma de poder que transforma a los individuos en sujetos.

Por lo demás, hemos podido incluso reparar que esta situación de estimulación a la belleza física y al consumo, no sólo viene desde el sistema de consumo, o desde los medios de comunicación de masas, sino desde las mismas personas en relaciones microfísicas de poder. Vale decir, la norma cultural que señala a la delgadez como promotora de éxito, no es suscitada sólo a partir de una instancia exterior, sino que esta se mueve a través de todas las relaciones sociales. Corroborando la premisa foucaultiana de que una vez establecida una norma cultural, la vigilancia, el disciplinamiento y la normalización, corren por relaciones y direcciones de poder múltiples. 
Quizás, uno de los inconvenientes a la hora de entender este tipo de temáticas guiados por Foucault y asociándolas al consumo y la belleza física, pasan por cómo pensar la producción del propio cuerpo, por ejemplo con la cirugía estética, a través de operatividad de mecanismos de poder, diferenciándola entre acción propia o actividad inducida. El ser libre en un cuerpo disciplinado o la libertad situada en el dominio del cuerpo.

En otras palabras, cómo distinguimos ese "trabajo sobre sí" que Foucault vincula con la "autoproducción”, con la creatividad y con la práctica de las operaciones subjetivas, obra de la operatividad de un dispositivo de poder, de una acción que responde a una norma enseñada. Sería una tensión entre dos polos: operaciones sobre sí, fruto de la sujeción al poder (aunque aparezcan como "libertad" de consumo, de cambio, de ser sí mismo, etc.) y operaciones que representen la práctica de una libertad situada. La “... contraposición entre el sujeto que ejerce su autonomía en las prácticas de sí mismo y el sujeto completamente colonizado por resortes de poder. En el primer caso, la subjetividad se despliega en un ejercicio de la libertad; en el otro, la subjetividad es una materia dócil que vive la ficción de su libertad” (Castro 2008: 403).

Por último, la critica foucaultiana coloca al desnudo las estrategias y las tácticas de las relaciones de poder y de saber, con sus continuidades y desplazamientos, en el intento de fabricar un tipo de individualidad, de crear ciertas prácticas, valores, normas, etc. En consecuencia, el presente artículo revela uno de los problemas que el autor francés buscó demostrar en sus reflexiones, y es que el hombre para Foucault está sujeto: sujeto a su conciencia y a su propia voluntad. Estamos sujetos a producir la verdad desde el poder que la exige, que la necesita para funcionar, mas esta situación no necesariamente es inmutable. 


\section{Notas}

${ }^{1}$ Como diría Bauman parafraseando a Descartes “Compro, luego existo...” (Bauman 2007: $32)$.

2 "En nuestra sociedad, el hombre y la mujer reconocen que se les impulsa al consumo innecesario, y, sin embargo, siguen actuando tal como esperan de ellos quienes dominan la mecánica del consumismo” (Salvat 1975: 19).

${ }^{3}$ Bajo la lógica del pensamiento de Foucault son estrategias de poder sin un claro estratega. Las relaciones de poder deben ser pensadas como relaciones de fuerzas que se ejercen sobre acciones y bajo una intencionalidad, por lo que no son identificables con un grupo o institución por sí mismos.

${ }^{4}$ Foucault especifica que todo discurso, y toda relación de poder, implican un saber, un campo analítico, así en relación al consumo podemos ver que las grandes empresas a fin de lograr mayor consumo han recurrido a psicólogos, semiólogos, publicistas, sociólogos, etc. Con el fin de ver el impacto de ciertas imágenes o productos en la mente del consumidor.

${ }^{5}$ Pages-Delon citado por Le Breton (2002) sostiene que las apariencias personales son una especie de "capital” para los actores sociales. Lo llama "Capital apariencia”.

${ }^{6}$ En los hombres el arquetipo obedecería a un cuerpo magro, sin tejido adiposo, bíceps protuberantes y abdominales sobresalientes, además de una estatura elevada.

${ }^{7}$ Para Simmel, “la moda es imitación de un modelo dado y proporciona así satisfacción a la necesidad de apoyo social; conduce al individuo al mismo camino por el que todos transitan” (Simmel 2002: 44).

8 "Hoy, los logros de la medicina y la biología (transplantes, transfusiones de sangre, prótesis, manipulaciones genéticas, procreación asistida, etc.) abren el camino para prácticas nuevas que cuentan con un futuro promisorio. Le dieron al cuerpo un valor de objeto cuyo precio es inestimable para una demanda cada vez mayor” (Le Breton 2002: 75).

${ }^{9}$ En el caso de los morenos la discriminación depende de la posición geográfica.

${ }^{10}$ La anorexia o la bulimia más que anómalas son extensiones lógicas de la norma imperante en la actual sociedad. 


\section{Bibliografía}

Aguirre, Patricia (2004), Ricos flacos y gordos pobres. La alimentación en crisis. Editorial Capital Intelectual, Buenos Aires.

Amigo, Isaac (2002), La delgadez imposible. La lucha contra la imposición de la imagen. Editorial Paidós, Barcelona.

Amigot, Patricia y Pujal, Margot (2006), “Ariadna danza: lecturas feministas de Michel Foucault”. Athenea Digital, 9, 100-130. Disponible en http://antalya.uab.es/athenea/num9/amigot.pdf.

Avenatti de Palumbo, Cecilia Inés (2006), “Lo bello une, lo bello viene de Dios”. Humanidades 6, no. 1 (diciembre 2006): 135-146. Fuente Académica, EBSCOhost (accessed July 24, 2008).

Bauman, Zygmunt (2000), Trabajo, consumismo y nuevos pobres. Editorial Gedisa, Barcelona.

Ídem (2007), Vida de consumo. Editorial Fondo de Cultura Económica, México.

Ídem (2006), Modernidad líquida. Editorial Fondo de Cultura Económica, Argentina.

Bayo-Borras, Regina (2008), “Cuando no hay palabras para decirlo hay un cuerpo para expresarlo”. (Español). Debate Feminista 37.19 (Abr. 2008): 199-210. Fuente Académica. 17 July 2008.

Biber, Adriana (2002), Anorexia. Cuando no se acepta el propio cuerpo. Ediciones FAPA, Barcelona.

Bourdieu, Pierre (1988), La distinción. Criterios y bases sociales del gusto. Editorial Taurus, Madrid.

Ídem (1986), “Notas provisionales sobre la percepción social del cuerpo”, en Materiales de Sociología Crítica, Álvarez-Uría, F. y Varela, J. (eds.), Editorial La Piqueta, Madrid. Pág. 183- 194.

Britos, María del Pilar (2008), “La problematización de la relación con la verdad. Interrogantes a partir de la lectura de Foucault”. Tópicos (Sta. Fe). [online]. 2005, no.13 [citado 07 Agosto 2008], p.29-43.

Ídem, "Michel Foucault: Del orden del discurso a una pragmática de lo múltiple”. Tópicos (Sta. Fe). [online]. 2003, no.11 [citado 11 Mayo 2009], p.63-82.

Cabrices, Rafael Osío (2007), "La pujante industria de los sacerdotes del cuerpo”. (Spanish). Debates IESA 12, no. 3 (July 2007): 66-72. Fuente 
Académica, EBSCOhost (accessed July 24, 2008).

Castaños, Nora, Claudia González, y José Manuel Ruiz (2008), “Belleza y ganancias para su vida”. (Spanish). Entrepreneur México 13.10 (Oct. 2005): 68-74. Fuente Académica. EBSCO. 17 July 2008

Castells, Manuel (1999), La era de la información: economía, sociedad y cultura. Vol.1 la sociedad red. Editorial Alianza, Madrid.

Castro, Edgardo (1995), Pensar a Foucault. Interrogantes filosóficos de La arqueología del saber. Editorial Biblos, Buenos Aires.

Ídem, “Michel Foucault: sujeto e historia”. Tópicos (Sta. Fe). [online]. ene./dic. 2006, no.14 [citado 15 Mayo 2009], p.171-183.

Castro Orellana, Rodrigo, “Ética y Libertad: La pars construens de la filosofía foucaultiana”. Rev. filos. [Online]. 2006, vol.62 [citado 07 Agosto 2008], p.117-138.

Ídem (2008), Foucault y el cuidado de la libertad. Ética para un rostro de arena. Editorial LOM, Santiago, Chile.

Colombo, Jorge Luís (2006), Comer todo o comer nada. Anorexia nerviosa, bulimia nerviosa y otros trastornos relacionados. Editorial Lumen, Buenos Aires.

Cuadra, Assumpta Rigo, “El otro cuerpo de la identidad: análisis de modelos culturales de los trastornos del cuerpo femenino. Cultura de los Cuidados” (Mar. 2006): 47-54. Fuente Académica. EBSCO. 17 July 2008.

Deleuze, Gilles (1987), Foucault. Editorial Paidos, Barcelona.

De La Escalera, Ana María, “Contando las maneras para decir el cuerpo”. (Spanish). Debate Feminista 36.19 (Oct. 2007): 3-8. Fuente Académica. EBSCO. 17 July 2008.

De La Parra, Marco Antonio (2002), El cuerpo de Chile. Editorial Planeta. Santiago, Chile.

Díaz, Esther, (1995), La filosofía de Michel Foucault. Editorial Biblos, Buenos Aires.

Díaz, Steffan Igor Ayora, “El cuerpo y la naturalización de la diferencia en la sociedad contemporánea.” (Spanish). Nueva Antropología: Revista de Ciencias Sociales 20.67 (May 2007): 89-118. Fuente Académica. EBSCO. 17 July2008.

Eco, Humberto (2007), Historia de la belleza. Editorial Lumen, Italia. 
Polis, Revista de la Universidad Bolivariana, Volumen 10, $N^{\circ}$ 28, 2011

Entrevista con Michel Foucault, Rev. Asoc. Esp. Neuropsiq. [online]. 2009, vol.29, n.1 [citado 2009-07-01], pp. 137-144

Ewen, Stuart (1992), Todas las imágenes del consumismo. La política del estilo en la cultura contemporánea. Editorial, Grijalbo, México.

Foucault, Michel (1998c), Vigilar y Castigar. Nacimiento de la prisión. Editorial Siglo Veintiuno, México.

Ídem (2006b), Los Anormales. Curso en el Collège de Francia (1974-1975) Editorial Fondo de Cultura Económica, México.

Ídem (1998a), Historia de la sexualidad. 1.- La voluntad de saber. Editorial Siglo Veintiuno, México.

Ídem (1998b), Historia de la sexualidad. 2.- El uso de los placeres. Editorial Siglo Veintiuno, México.

Ídem (1992b), Historia de la sexualidad. 3.- La inquietud de sí. Editorial Siglo Veintiuno, México.

Ídem (2000a), Tecnología del yo. Y otros textos afines. Editorial Paidós, Barcelona.

Ídem (1992a), Microfísica del poder. Editorial La Piqueta, Madrid..

Ídem (1993), La vida de los hombres infames. Ensayos sobre desviación y dominación. Editorial Altamira, Buenos Aires.

Ídem (1988), Un diálogo sobre el poder y otras conversaciones. Editorial Alianza, Madrid.

Ídem (2006a), Historia de la locura en la época clásica I. Editorial Fondo de Cultura Económica, México.

Ídem (2007), Historia de la locura en la época clásica, II. Editorial Fondo de Cultura Económica, México.

Ídem (1999), La arqueología del saber. Editorial Siglo Veintiuno, México.

Ídem (2000b), Defender la sociedad. Curso en el Collège de Francia (19751976). Editorial Fondo de Cultura Económica, Buenos Aires.

Ídem (2001), Las palabras y las cosas. Una arqueología de las ciencias humanas. Editorial Siglo Veintiuno, México.

Ídem (2008), Nacimiento de la biopolítica. Curso en el Collège de Francia (1978- 1979). Editorial Fondo de Cultura Económica, Buenos Aires. 
Ídem (1991), Saber y verdad. Editorial La Piqueta, Madrid.

Ganter, S. Rodrigo (2006), "De cuerpos, tatuajes y culturas juveniles. (Spanish).” Espacio Abierto. Cuaderno Venezolano de Sociología 15, no. 1/2 (January 2006): 427-453. Fuente Académica, EBSCOhost (accessed July 24, 2008).

Gil-Romo, Sara, Elena Pérez, Vega-García Luz Amaranta, Romero-Juárez Gabriela (2007), "Prácticas alimentarias de mujeres rurales: ¿una nueva percepción del cuerpo?”, Salud pública Méx. [Periódico na Internet]. 2007 Fev [citado 2008 Jun 04]; 49(1): 52-62.

Giménez, Fabián (2008), “Pornografía hipertélica: cuerpo y obscenidad en el arte contemporáneo. (Spanish).” Fuentes Humanísticas 34 (Oct. 2007): 1-21. Fuente Académica. EBSCO. 17 July 2008.

Goffman, Irving (2004), La presentación de la persona en la vida cotidiana. Editorial Amorrortu, Buenos Aires.

Ídem (1995), Estigma. La identidad deteriorada. Editorial Amorrortu, Buenos Aires.

Gómez, Benjamín (2005), “Ética y medicina en Michel Foucault: la dimensión humanística de la medicina a partir de una genealogía de la moral”, Hist. cienc. saude-Manguinhos, Río de Janeiro, v. 12, n. 3, Dec. 2005.

Iglesias Bello, Mariana (2005), "La Mujer de hoy: Riesgos en la búsqueda de la imagen corporal perfecta.” An Venez Nutr. [En línea]. 2005, vol.18, no.1 [citado 28 Julio 2008], p.113-115.

Kepp, Michael (2008), “Belleza exportadora. (Spanish).” Latin Trade (Spanish) 13.6 (June 2005): 26-26. Fuente Académica. EBSCO. 17 July 2008.

Le Breton, David (2002), La sociología del cuerpo. Ediciones Nueva Visión, Buenos Aires.

Llaguno, Marta Martín (2008), “La tiranía de la apariencia en la sociedad de las representaciones. (Spanish).” Revista Latina de Comunicación Social 5.50 (May 2002): 16. Fuente Académica. EBSCO. 17 July 2008.

Madrazo, Jorge Ariel (2006), “Belleza, sí, pero ¿qué es eso?”, Atenea (Concepc.). [online]. 2006, no.493 [citado 05 Junho 2008], p.11-22.

Marin B., Verónica (2002), “Trastornos de la conducta alimentaria en escolares y adolescentes”, Rev. chil. nutr. [online]. 2002, vol.29, n.2 [citado 2009-07-01], pp. 86-91. 
Mijares Gil, Alejandro (2006), “La estética y la humanidad.” Acta odontol. venez. [online]. jan. 2006, vol.44, no.1 [citado 05 Junho 2008], p.139141.

Montesino, Sonia; René Castro y Marco Antonio De La Parra (Compiladores) (2003), Mujeres espejos y fragmentos. Antropología del género y salud en el Chile del siglo XXI. Editorial Aconcagua, Santiago, Chile.

Moreno L, Arturo y Toro Z, Luis (2009), “La televisión, mediadora entre consumismo y obesidad”. Rev. chil. nutr. [online]. 2009, vol.36, n.1 [citado 2009-06-29], pp. 46-52.

Morris, Desmond (2005), La mujer desnuda. Un estudio del cuerpo femenino. Editorial Planeta, Barcelona.

Moulian, Tomás (1999), El consumo me consume. Editorial LOM, Santiago, Chile.

Paquet, Dominique (1998), La historia de la belleza. Editorial Grupo Zeta, Barcelona.

Pedraza Gómez, Zandra, “Cuerpo e investigación en teoría social” (Accessed May 22, 2008). http://antropologia.uniandes.edu.co/zpedraza/zp1.pdf.

Perena García, Francisco (2007), “Cuerpo y subjetividad: acerca de la anorexia”, Rev. Esp. Salud Publica. [online]. 2007, vol. 81, no. 5 [citado 200806-04], pp. 529-542.

Porzecanski, Teresa (Comp.) (2008), El cuerpo y sus espejos. Estudios antropológicos culturales. Editorial Planeta. Montevideo, Uruguay.

Ramírez, Ingrid Johanna Bolívar, "Reinados de belleza y nacionalización de las sociedades latinoamericanas. (Spanish).” Íconos. Revista de Ciencias Sociales (May 2007): 71-80. Fuente Académica. EBSCO. 17July2008.

Ramos, Mila, "Cuando el cuerpo de las mujeres se convierte en campo de batalla. (Spanish).” Tiempo de Paz (Mar. 2007): 34-36. Fuente Académica. EBSCO. 17 July 2008.

Retamal, Christia (2008), “Consideraciones sobre poder y dominación en la formación de la subjetividad moderna.” Universum [online]. 2008, vol.23, n.2 [citado 2009-06-03], pp. 166-183.

Rojas, Enrique (1994), El hombre Light. Una vida sin valores. Editorial Planeta. Santiago, Chile.

Salvat, Manuel (1975), La sociedad de consumo. Editorial Salvat, Barcelona. 
Salzinger, Leslie (2007), "De los tacones altos a los cuerpos acotados: significados generizados en (la) producción de la industria maquiladora para la exportación de México. (Spanish).” Debate Feminista 35.18 (Apr. 2007): 3-30. Fuente Académica. EBSCO. 17 July 2008.

Sánchez Rodríguez, Kyrenia y Alessandrini González, Roidel (2007), “Algunas consideraciones éticas sobre la cirugía plástica”, Rev Cubana Cir [online]. 2007, vol. 46, no. 4 [citado 2009-06-30].

Simmel, George (2003), Cuestiones fundamentales de sociología. Editorial Gedisa. Barcelona.

Ídem (2002), Sobre la aventura. Ensayos de estética. Editorial Península. Barcelona, España.

Turner, Bryan (1989), El cuerpo y la sociedad. Exploraciones en la teoría social. Editorial Fondo de Cultura Económica. Ciudad de México, México.

Valor, M. Luisa Gea (2007), “El culto a la salud y la belleza. La retórica del bienestar. (Spanish).” Revista Española de Lingüística Aplicada 20 (Apr. 2007): 227-229. Fuente Académica. EBSCO. 17 July 2008.

Vicente Pedraz, Miguel (2007), “La construcción de una ética médicodeportiva de sujeción: el cuerpo preso de la vida saludable.” Salud pública Méx [periódico na Internet]. 2007 Fev [citado 2008 Jul 28]; 49 (1): 71-78.

Recibido: 15.02.2010

Aceptado: 03.12.2010 